\title{
HEMIPLEGIA ALTERNA TIPO WEBER PRODUZIDA POR HERNIA DO UNCUS HIPOCAMPAL
}

\author{
OSWALDO RICCIARDI CRUZ * \\ L. C. MATTOSINHO FRANCA **
}

A sindrome de Weber subentende, como é sabido, lesão mesencefálica atingindo a via corticospinal e as fibras do nervo óculo-motor. Em 1946 (Hemiplegia alterna tipo Weber sem lesão peduncular, Arq. Neuro-Psiquiat., 4: 118, junho, 1946) foi publicado por A. Caetano da Silva Jr. um caso de hemiplegia alterna de tipo peduncular sem lesão mesencefálica; a lesão, hematoma, comprometia o nervo óculo-motor fora do eixo nervoso e comprimia o pedúnculo cerebral produzindo hemiplegia controlateral.

A razão do registro de mais êste caso repousa na raridade com que lesões extramesencefálicas se manifestam de modo a simular lesão intrapeduncular e também porque o mecanismo de produção do quadro clínico, neste caso, é diverso daquele verificado pelo autor acima citado.

M. L. G. (reg. 362.625), feminina, branca, com 48 anos de idade. Um ano antes da internação começou a sentir cefaléia frontal intensa e baixa progressiva da visão coo ôlho direito. Há 15 dias acordou durante a noite com intensa cefaléia e vômitos; em seguida obnublação, queda da pálpebra direita e paralisia dos membros do hemicorpo esquerdo. Nos antecedentes e no exame físico nada havia digno de nota; pressão arterial $160 \times 90$, pulso 80 , afebril. Ao ser atendida no Pronto Socorro, apresentava: paralisia do III par craniano à direita, hemiparesia desproporcionada no hemicorpo esquerdo, mais acentuada no membro inferior e rigidez de nuca. Os fundos oculares eram normais e o liqüido cefalorraqueano, obtido por punção suboccipital, era francamente hemorrágico; a manometria revelou pressão inicial de $40 \mathrm{~cm}$ de água. Internada, o estado da paciente foi se agravando até o coma. A angiografia, feita mediante injeção de contraste na carótida externa, mostrou a existência de aneurisma pediculado na parte média do segmento horizontal da artéria cerebral anterior direita (fig. $1 \mathrm{~A}$ ); à esquerda observava-se oclusão do segmento horizontal da artéria cerebral anterior (fig. $1 \mathrm{~B}$ ). Convém observar que a artéria ceIebral anterior esquerda recebe sangue proveniente da carótida direita, através da comunicante anterior (fig. $1 \mathrm{~A}$ ).

Tendo sido a sintomatologia relacionada à hemorragia maciça proveniente da rotura do aneurisma, foi a paciente operada em caráter de urgência. Aberta a duramater, verificou-se a presença de coágulo laminar que cobria a superficie convexa do lobo frontal. O aneurisma repousava sôbre o quiasma óptico e achava-se envolto por coágulos sangüineos; seu pedículo sangrava com as manobras de isolamento. $\mathrm{O}$

* Plantonista de Neurocirurgia do Pronto Socorro do Hospital das Clínicas da Fac. Med. da Univ. de São Paulo (Prof. A. Tolosa).

* Médico interno do Hospital das Clínicas pelo Departamento de Anatomia Patológica da Fac. Med. da Univ. de São Paulo (Prof. L. Cunha Motta). 

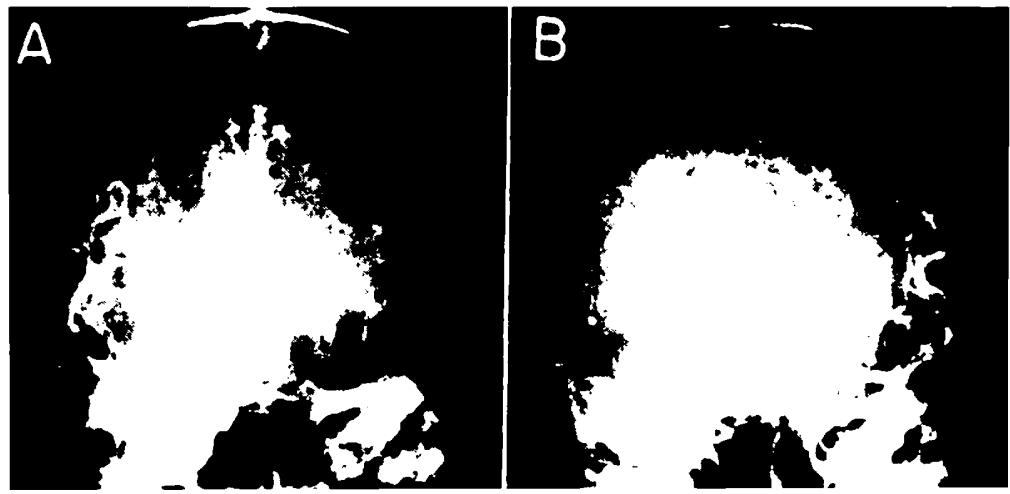

Fig. 1 - Caso M. L. G. Em A, angiografia cerebral direita mostrando aneurisma do segmento horizqntal da artéria cerebral anterior, e a passagem de contraste para o segmento distal da artéria cerebrai anterior esquerda; em $B$, angiografia cerebral esquerda mostrando ausência de todo segmento da cerebral anterior compreendido entre à extremidade distal da carótida e a comunicante anterior.

saco aneurismático foi extirpado mediante secção de seu pedículo prèviamente clipado na frente e atrás do nível de secção. Verificada a ausência de sangramento no campo, a craniotomia foi fechada. No pós-operatório foi necessário recorrer à traqueostomia em virtude de abundante secreção tráqueo-brônquica; com êsse recurso as funções respiratórias e a circulação melhoraram sensivelmente, mas a paciente permaneceu em estado de coma. No $5^{\circ}$ dia de pós-operatório, após apresentar alteraçōes respiratórias (Cheyne-Stokes), a paciente faleceu. Nada tendo sido encontrado durante a inspeção cirúrgica além da hemorragia meningea, foi a hemiplegia alterna explicada como produzida por hemorragia intrapeduncular.

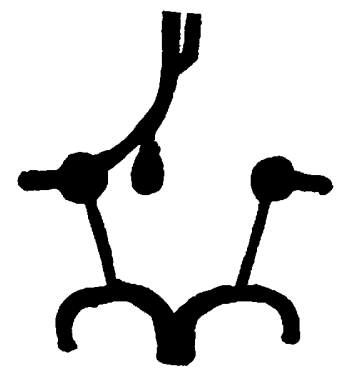

Fig. 2 - Caso M. L. G. Desenho esquemático mostrando as anomalias do polígono de Willis.

A necrópsia revelou aumento de volume do cérebro, com predominância do hemisfério direito. Hérnia de uncus direito com empurramento do nervo óculo-motor direito para a linha mediana e compressão da base direita do pedúnculo cerebral; arteriosclerose das artérias cerebrais, trombose do segmento horizontal $\left(A_{1}\right)$ da artéria cerebral anterior direita. Coágulos sangüíneos no espaço subaracnóideo da face orbitária do lobo frontal direito. Aos cortes do cérebro, foco hemorrágico de forma ovóide, com $3 \mathrm{~cm}$ no maior eixo, situado no lobo frontal direito, entre o giro reto e o corno frontal do ventrículo lateral; hemorragia ventricular secundária. Discreta dilataçāo do ventrículo lateral esquerdo. Mesencéfalo e rombencéfalo sem alterações. 
o exame histológico revelou, de interésse, exsudato inflamatório agudo na leptomeninge cerebral, e sinais de degeneração no nervo óculo-motor direito. O restante da necrópsia revelou áreas de broncopneumonia e trombose recente da carótida comum do lado direito.

\section{COMENTARIOS}

Em resumo, trata-se de paciente portadora de hipertensão arterial, referindo cefaléia moderada e perturbaçōes visuais, que apresentou quadro agudo caracterizado por intensa cefaléia, vômitos, obnubilação, ptose palpebral direita, hemiparesia esquerda, rigidez de nuca. A punção raquiana forneceu líquor hemorrágico. A carótido-angiografia mostrou aneurisma pediculado da artéria cerebral anterior direita, e oclusão do segmento horizontal da artéria cerebral anterior esquerda.

Após a intervenção cirúrgica (ligadura do pedículo do aneurisma e retirada de coágulos sangüíneos subaracnóideos) o raciocínio clínico foi orientado no sentido de ser a sindrome de Weber causada por hemorragia intrapeduncular; o aneurisma da cerebral anterior e o pequeno volume da hemorragia extra-encefálica não poderiam explicar a hemiplegia alterna; quando muito, o aneurisma, pela sua situação, explicaria a perda progressiva da acuidade visual. O exame necroscópico revelou presença de pequena quantidade de sangue nas vizinhanças do local do aneurisma ressecado e foco de hemorragia no interior do lobo frontal direito; o hemisfério cerebral direito, bastante edemaciado, apresentava hérnia de uncus que comprimia o nervo óculomotor direito e base direita do pedúnculo cerebral, deslocando-os para a linha mediana e determinando, assim, a hemiplegia alterna.

A ausência de continuidade entre o foco hemorrágico do lobo frontal direito e a hemorragia meníngea depõe a favor de processos simultâneos porém independentes entre si; de fato o foco hemorrágico situado na intimidade do lobo frontal não apresentava escoamento quer para o espaço subaracnóideo, quer para o sistema ventricular. O hemisfério cerebral direito, sede da hemorragia, apresentava acentuado edema caracterizado por menor capacidade do ventrículo lateral direito e pela hérnia de uncus.

Se os sintomas e sinais clínicos nos permitem rotular êste caso como síndrome de Weber, clàssicamente considerada como característica das lesões intrapedunculares, os achados anátomo-patológicos nos levam a interpretação diversa.

A ausência de lesões mesencefálicas, e conseqüentemente a integridade do núcleo e das fibras intramesencefálicas do nervo óculo-motor, impõem a correlação dos sinais clínicos com a compressão exercida pela hérnia de uncus sôbre a base direita do pedúnculo cerebral e sôbre o tronco do nervo óculomotor.

Neste caso, portanto, trata-se de hemiplegia alterna - tipo Weber resultante da compressão do mesencéfalo e do nervo óculo-motor direito por hérnia de uncus resultante de edema hemisférico, êste último secundário a hemorragia intracerebral na intimidade do lobo frontal. O aneurisma arte- 
rial explicaria a perda visual do ôlho direito; a hemorragia meníngea seria responsável pela cefaléia e rigidez da nuca.

RESUMO

Os autores apresentam um caso de falsa sindrome de Weber decorrente da compressão exercida sôbre o mesencéfalo e nervo óculo-motor por hérnia de uncus resultante de edema hemisférico secundário a hemorragia intracerebral localizada no lobo frontal.

\section{SUMMARY}

Case report of false syndrome of Weber due to a subarachnoid hemorrhage, with uncal hernia compressing the mesencephalon and oculo motor nerve on the right side.

Clinica Neurológica. Hospital das Clínicas da Fac. Med. da Univ. de São PauloCaixa Postal 3461 - São Paulo, Brasil. 